\title{
O Conceito de Leitura nos Documentos Oficiais
}

The Concept of Reading in Official Documents

Renilson José MENEGASSI *

Angela Francine FUZA **

Resumo: Analisam-se os principais documentos oficias do Brasil que fundamentam a prática da leitura, a fim de verificar os conceitos de leitura por eles demarcados. Assim, são destacados, primeiramente, os pressupostos sobre leitura apresentados nos Parâmetros Curriculares Nacionais (PCN, BRASIL, 1998); posteriormente, aqueles presentes nas Diretrizes Curriculares Estaduais de Língua Portuguesa (DCE, PARANÁ, 2008), por fim, os discutidos nos documentos referentes ao Sistema Nacional de Educação Básica (Saeb), a partir do foco da Matriz de Referência da Prova Brasil. Os resultados das análises mostram que, de modo geral, o conceito de leitura que perpassa pelos documentos oficiais investigados é a perspectiva interacionista, uma vez que a linguagem é tida como uma forma de interação entre os sujeitos.

Palavras-chave: Leitura; Conceito; Documento oficial.

Abstract: The aims of this research are to analyze the mainly official documents that subsidize the practice of reading and to verify their concept of reading. First of all, it is pointed out the assumptions about reading showed in the Parâmetros Curriculares Nacionais (PCN, BRASIL, 1998); after, the ideas presented by Diretrizes Curriculares Estaduais de Língua Portuguesa (DCE, PARANÁ, 2008), finally, the ideas discussed in the documents related to Sistema Nacional de

* Doutor em Letras pela Universidade Estadual Júlio de Mesquita Filho (UNESP-Assis). Docente da Universidade Estadual de Maringá. Contato: renilson@wnet.com.br.

** Mestre em Letras pela Universidade Estadual de Maringá. Contato: angelafuza@hotmail.com. 
Educação Básica (SAEB), considering the focus in the Matriz de Referência of Prova Brasil. The results show that in the official documents there is the interactive concept of reading, since the language is considered a form of interaction among people.

Key-words: Reading; Concept; Official document.

\section{Introdução}

O ensino da leitura e da escrita é umas das principais tarefas da escola, já que se configurou como importante instrumento para que as pessoas exerçam seus direitos, possam trabalhar, participar da sociedade, aprender e desenvolver novas habilidades ao longo da vida. No contexto escolar, a leitura e a escrita são fundamentais em qualquer uma das disciplinas, por isso, em cada ano escolar, o aluno precisa desenvolver capacidades, habilidades e estratégias de ler e de escrever, para atender às demandas curriculares.

Mesmo vivendo na época denominada como "Era da Informação", que possibilita o acesso rápido à leitura de diferentes textos, constata-se, de acordo com dados do Instituto Nacional de Estudos e Pesquisas Educacionais Anísio Teixeira-Inep (on line, acesso em 23-01-2010), o alto índice de analfabetos funcionais, ou seja, pessoas que dominam o código linguístico, porém não desenvolveram habilidades de compreensão e interpretação. O Brasil apresenta cerca de 16 milhões de analfabetos com quinze anos ou mais e 30 milhões de analfabetos funcionais. Diante desse quadro, estudos, como o "Mapa do Analfabetismo no Brasil" (INEP, on line, 23-01-2010), são realizados, assim como avaliações oficiais de leitura, visando à melhoria da qualidade da educação, especificamente no que se refere à leitura.

Dessa forma, a partir dos conceitos de leitura conhecidos pela literatura de Linguística Aplicada, nas perspectivas do texto, do leitor e da interação autor-texto-leitor, discutidas por vários autores (DELL'ISOLA, 1996; KLEIMAN, 1996; 2000; LEFFA, 1996; MENEGASSI e ANGELO, 2005), centrando-se na perspectiva interacionista, são analisados os principais documentos oficiais do Brasil que fundamentam a prática da leitura, a fim de verificar os conceitos de leitura por eles demarcados. Dessa forma, são destacados, 
primeiramente, os pressupostos sobre leitura apresentados nos Parâmetros Curriculares Nacionais (PCN, BRASIL, 1998); posteriormente, aqueles presentes nas Diretrizes Curriculares Estaduais de Língua Portuguesa (DCE, PARANÁ, 2008), por fim, os discutidos nos documentos referentes ao Sistema Nacional de Educação Básica (Saeb), a partir do foco da Matriz de Referência da Prova Brasil. ${ }^{1}$

\section{A leitura nos PCN}

Em relação ao ensino e a aprendizagem da leitura, os Parâmetros Curriculares Nacionais (BRASIL, 1998, p. 40) afirmam categoricamente que "o trabalho com a leitura tem como finalidade a formação de leitores competentes". Ao utilizar a expressão "trabalho com a leitura", ao invés de "ato de leitura", postula-se que a atividade configura-se como um processo coletivo e não individual, em que professor, aluno e autor, através do texto, dialogam em busca de possíveis leituras, não havendo a predominância de um desses elementos no processo de leitura. Além disso, a finalidade da atividade é, primeiramente, a formação do leitor e não o seu desenvolvimento (MENEGASSI, 2010), haja vista que é necessário que o aluno passe pelas fases de formação, lendo diferentes textos, até alcançar o desenvolvimento em leitura, momento em que se apropria daquilo que lê, trazendo à sua realidade, realizando inferências, entre outras atividades de letramentos sociais, não apenas o escolar, para a formação do leito competente.

Os PCN ainda postulam que a leitura

[...] é um processo no qual o leitor realiza um trabalho ativo de construção do significado do texto, a partir de seus objetivos, do seu conhecimento sobre o assunto [...] não se trata

\footnotetext{
${ }^{1}$ Os documentos foram ordenados dessa forma, uma vez que os pressupostos postulados pelo Saeb, como a Matriz de Referência da Prova Brasil, tiveram como fundamento as teorias expostas pelos PCN (BRASIL, 1998), assim como as teorias demarcadas nos currículos estaduais vigentes no Brasil, como as DCEs do Paraná. Cabe ressaltar, especificamente, que os PCN, assim como as DCEs, são exemplificações de como a teoria interacionista de leitura é apresentada em documentos oficiais nos âmbitos Nacional e Estadual.
} 
simplesmente de extrair informações da escrita, decodificandoa letra por letra, palavra por palavra. Trata-se de uma atividade que implica, necessariamente, compreensão. (BRASIL, 1998, p. 41)

Observa-se que a leitura é tida como um processo, ou seja, constituída de etapas que exigem um trabalho de construção de significado do texto por parte do leitor. O significado é aquele demarcado no texto e o aluno é responsável por buscá-lo, visando à produção de sentidos para aquilo que lê, que são produzidos a partir de suas relações sócio-histórico-ideológicas com o texto. Primeiramente, ele extrai as ideias, faz sua compreensão e, a partir disso, produz os sentidos possíveis para o texto que leu. Os PCN (BRASIL, 1998) demarcam ainda que a decodificação, referente ao primeiro conceito de leitura, é apenas um dos procedimentos que o indivíduo utiliza ao ler, pois a leitura fluente envolve outras estratégias, como seleção, antecipação, inferência e verificação.

Diante da afirmação dos PCN (BRASIL, 1998), verifica-se a visão de leitura interacionista, pois a leitura é tida como um processo; o leitor realiza um trabalho ativo; o leitor constrói significados do texto; o leitor tem objetivos de leitura e ele não apenas extrai informações do texto, mas também as compreende. Constata-se, assim, a leitura como um processo de interação entre leitor e texto, promovendo-se a atitude ativa do sujeito diante daquilo que lê, o que possibilita a formação e o desenvolvimento do leitor competente.

Embora haja a necessidade de se conceber a leitura como um processo de interação, os PCN (BRASIL, 1998) afirmam que é importante superar algumas concepções sobre o aprendizado inicial da leitura:

A principal delas é a de que ler é simplesmente decodificar, converter letras em sons, sendo a compreensão conseqüência natural dessa ação. Por conta desta concepção equivocada a escola vem produzindo grande quantidade de "leitores" capazes de decodificar qualquer texto, mas com enormes dificuldades para compreender o que tentam ler. (BRASIL, 1998, p. 43). 
Verifica-se que o ato da leitura vai além da decodificação, reafirmando a necessidade de se interagir as perspectivas de leitura com focos no texto e no leitor, a fim de alcançar a interação entre eles. É preciso que se ofereçam ao leitor oportunidades de aprendere a ler a partir da antecipação de ideias, da realização de inferências e da retomada de conhecimentos prévios, ultrapassando o nível da decodificação tão presente nos materiais feitos exclusivamente para ensinar a ler na escola, nos dizeres dos PCN (1998).

Assim, concebe-se a leitura como uma prática social, um meio de possibilitar a realização de novos diálogos entre os sujeitos envolvidos no processo: o autor, representado pelo texto, e o leitor, uma resposta a uma necessidade, em práticas de letramentos socialmente determinadas. Logo,

Fora da escola, não se lê só para aprender a ler, não se lê de uma única forma, não se decodifica palavra por palavra, não se responde a perguntas de verificação do entendimento preenchendo fichas exaustivas, não se faz desenho sobre o que mais gostou e raramente se lê em voz alta. (BRASIL, 1998, p. 44).

Se o indivíduo utiliza a leitura com uma forma de ação nas situações presentes no seu contexto social, não se pode, então, considerála como repetição infindável de atividades escolares que visam, por exemplo, a uma única forma de leitura ou ao preenchimento de fichas exaustivas. Dessa forma, a prática constante de leitura na escola pressupõe o trabalho com a diversidade de objetivos, modalidades e textos. Ela deve admitir várias leituras, superando o mito da interpretação única, fruto do pressuposto de que o significado está dado no texto, correspondendo à perspectiva do texto: "O significado, no entanto, constrói-se pelo esforço de interpretação do leitor, a partir não só do que está escrito, mas do conhecimento que traz para o texto.” (BRASIL, 1998, p. 44). Dessa forma, informações são extraídas do texto e também atribuídas pelo leitor, durante o processo da leitura, construindo-se o processo de interação de diálogo.

Diante dos aspectos apresentados pelos PCN (BRASIL, 1998), destacam-se, na sequência, as características sobre leitura observadas: 


\begin{tabular}{|l|}
\hline $\begin{array}{l}\text { A leitura leva à formação e ao desenvolvimento de leitores } \\
\text { competentes. }\end{array}$ \\
\hline A leitura é um processo coletivo. \\
\hline A leitura é constituída por etapas. \\
\hline $\begin{array}{l}\text { O leitor realiza um trabalho ativo de construção do significado do } \\
\text { texto. }\end{array}$ \\
\hline O leitor tem objetivos de leitura. \\
\hline A leitura implica compreensão. \\
\hline
\end{tabular}

Quadro 1 - Características sobre a leitura nos PCN.

Tem-se, assim, a leitura concebida como uma forma de interação, perpassando diversas etapas até chegar a sua interpretação.

\section{A leitura nas DCE-PR}

A partir dos PCN (BRASIL, 1998), outros documentos em esferas estaduais foram desenvolvidos, num processo de amadurecimento, desenvolvimento e expansão dos pressupostos teóricos expostos, como as Diretrizes Curriculares Estaduais - DCE (PARANÁ, 2008). Esse documento é resultante de um longo processo de discussão coletiva, ocorrido entre 2004 e 2008, que envolveu os professores da Rede Estadual de Ensino da Educação Básica do Paraná, consideradas, no momento, como fundamento para o trabalho pedagógico na escola.

De acordo com os DCE, o ensino de Língua Portuguesa ainda segue, em alguns contextos, uma concepção de linguagem que não privilegia a história, o sujeito e o contexto de produção, restringindo a leitura e a escrita ao estudo apenas da nomenclatura da gramática tradicional. Essa visão de língua como estrutura não é defendida pelas DCE, que assumem explicitamente uma concepção de linguagem que se abre para sua condição de atividade e acontecimento social, numa proposta interacionista:

As Diretrizes ora propostas assumem uma concepção de linguagem que não se fecha "na sua condição de sistemas de formas, mas se abre para a sua condição de atividade e 
acontecimento social, portanto, estratificada pelos valores ideológicos” (RODRIGUES, 2005, p. 156). Nesse sentido, a linguagem é vista como fenômeno social, pois nasce da necessidade de interação (política, social e econômica) entre os homens. (PARANÁ, 2008, p. 49)

Acredita-se, assim, que ensinar a língua requer que se considerem os aspectos sociais e históricos em que o sujeito está inserido, bem como o contexto de produção do texto, aprimorando os conhecimentos linguísticos e discursivos dos alunos, a fim de terem condições de interagir em diferentes situações sociais. Para que tais objetivos sejam alcançados, cabe ao professor promover a prática, a discussão e a leitura de textos das diferentes esferas sociais, garantindo o envolvimento do aluno com as práticas discursivas, fazendo com que haja o uso efetivo da linguagem.

A partir dessas ideias, observa-se que a concepção de linguagem defendida pelas DCE tem como foco a interação, buscando o diálogo entre os conhecimentos presentes na escola e aqueles trazidos pelos alunos. De acordo com Souza (2010), as diversas versões das Diretrizes Curriculares Estaduais de Língua Portuguesa adotam a Teoria Enunciativa de linguagem que, no Brasil, nos aspectos relativos ao ensino de línguas, assume a nomenclatura de interacionismo. Para as DCE (PARANÁ, 2008, p. 1-81), “[...] é animador o fato de a maioria dos professores reconhecer que, no atual contexto, a concepção/teoria que mais se presta ao processo de ensino aprendizagem de língua é a Interacionista ou da Enunciação/Discurso".

As práticas discursivas de oralidade, escrita e leitura, aqui centrando-se a discussão nesta última, devem possibilitar o contato do aluno com a linguagem nas diferentes esferas sociais para o desenvolvimento da capacidade de compreensão dos sentidos do texto, suas intenções e visão de mundo. Há, assim, a preocupação em propor um trabalho pedagógico que priorize as práticas sociais de linguagem. Nesse sentido, as DCE, utilizando-se dos dizeres de Bunzen (2006), propõem que os gêneros discursivos que se apresentam no cotidiano dos alunos sejam legitimados na escola, numa busca de relacionar as práticas de letramentos sociais às práticas de letramento escolar: 
As práticas discursivas presentes nos diversos gêneros que fazem parte do cotidiano dos educandos podem ser legitimadas na escola. Isso colaboraria com a não fragmentação entre a língua e a vida do aluno, uma vez que na escola ele não leria e produziria apenas textos escolares, didatizados, mas teria contato com os textos presentes nos diversos espaços de socialização que freqüenta. (PARANÁ, 2008, p. 53).

Vê-se, então, o foco em fazer com que os alunos utilizem a linguagem por meio dos gêneros que circulam em seu meio social, reforçando a visão interacionista de linguagem que postula a sua prática social em diversas situações, corroborando os pressupostos pelos PCN. Para as DCE (PARANÁ, 2008), é nessa dimensão dialógica que a leitura deve ser experenciada, desde a alfabetização, o que expande necessariamente os pressupostos dos PCN, numa mostra de desenvolvimento conceitual nos documentos oficiais. Ao reconhecer as vozes e as ideologias presentes no discurso, possibilita-se a construção de sentidos ao texto e a compreensão das relações de poder que são inerentes a ele. Dessa forma, "todo texto é, assim, articulação de discursos, vozes que se materializam, ato humano, é linguagem em uso efetivo [...] o texto é sempre uma atitude responsiva a outros textos" (PARANÁ, 2008, p. 51), retomando-se a noção de responsividade discutida por Bakhtin (2003) e assumida pelo documento oficial paranaense.

Para as Diretrizes, é necessário que, no processo de ensinoaprendizagem, fique evidente que, quanto maior é o contato com a linguagem, mais possibilidades há de se entender o texto, seus sentidos, suas intenções e visões de mundo. Dessa forma, a ação pedagógica deve pautar-se na interlocução, em atividades planejadas que possibilitem ao estudante a leitura e a produção oral e escrita. Assim, as práticas pedagógicas são divididas pelas DCE em: oralidade, escrita e leitura.

A leitura, especificamente, é concebida, então, como um ato dialógico, havendo a interação, a interlocução entre texto e leitor. A compreensão realiza-se, assim, por meio de trocas de conhecimentos e informações (LEFFA, 1996). Vê-se que a leitura não se restringe à mera decodificação de elementos do texto, exigindo do leitor a busca de suas experiências, de seus conhecimentos prévios, a fim de que se 
manifeste sobre o que leu. Isso demonstra a noção de responsividade defendida por Bakhtin (2003), pois toda a compreensão de uma fala é sempre acompanhada de um ato responsivo, evidenciando o conceito de leitura como interação.

De acordo com as DCE (PARANÁ, 2008), a leitura se constitui "no ato da recepção", sendo o texto uma potencialidade significativa e o leitor um atualizador dos sentidos, por meio de atitudes responsivas. Assim, ao tratar o texto dialogicamente e discursivamente, possibilitase a constituição do leitor como sujeito, pois dialoga com o texto, relacionando-o com seus conhecimentos anteriores.

Ao considerar o contexto escolar como um ambiente de convívio com as múltiplas possibilidades de interlocução com os textos, as DCE apresentam alguns aspectos a serem considerados nas propostas de atividades de leitura:

$\mathrm{Na}$ sala de aula é necessário analisar, nas atividades de interpretação e compreensão de um texto: os conhecimentos de mundo do aluno, os conhecimentos lingüísticos, o conhecimento da situação comunicativa, dos interlocutores envolvidos, dos gêneros e suas esferas, do suporte em que o gênero está publicado, de outros textos (intertextualidade). (PARANÁ, 2008, p. 73)

Dessa forma, busca-se realizar o diálogo entre os conhecimentos trazidos pelo contexto escolar, assim como aqueles demonstrados pelo aluno, fazendo com que haja a compreensão da situação comunicativa e, consequentemente, a resposta ativa diante dos textos lidos, uma vez que o leitor "é visto como um sujeito ativo no processo, tendo voz em seu contexto.” (PARANÁ, 2008, p. 74).

A partir dos aspectos teóricos sobre a leitura demarcado nas DCE (PARANÁ, 2008), torna-se possível o levantamento das suas características: 


\begin{tabular}{|l|}
\hline A leitura é uma condição de atividade e acontecimento social. \\
\hline $\begin{array}{l}\text { A leitura considera aspectos sociais e históricos em que o sujeito } \\
\text { está inserido. }\end{array}$ \\
\hline $\begin{array}{l}\text { A leitura permite o contato do aluno com a linguagem nas } \\
\text { diferentes esferas sociais. }\end{array}$ \\
\hline A leitura é de dimensão dialógica. \\
\hline A ação pedagógica de leitura deve pautar-se na interlocução. \\
\hline $\begin{array}{l}\text { A leitura envolve demandas sociais, históricas, políticas, } \\
\text { econômicas, pedagógicas e ideológicas de um momento. }\end{array}$ \\
\hline $\begin{array}{l}\text { Ao ler, o indivíduo busca suas experiências e seus conhecimentos } \\
\text { prévios. }\end{array}$ \\
\hline A leitura implica uma resposta do leitor ao que lê. \\
\hline A leitura acontece num tempo e num espaço. \\
\hline O leitor se constitui como sujeito. \\
\hline
\end{tabular}

Quadro 2 - Características sobre a leitura nas DCE (PARANÁ, 2008)

Diante do exposto, vê-se a preocupação tanto dos PCN (BRASIL, 1998) quanto das DCE (PARANÁ, 2008), em promover um ensino de leitura centrado no diálogo, possibilitando-se a formação e o desenvolvimento de um leitor crítico, a partir do conceito interacionista de leitura.

\section{A leitura no SAEB}

A atenção voltada para o trabalho com a leitura no contexto escolar é constante, sendo assim, o Governo Federal, por meio do Ministério da Educação (MEC), lançou, em 2007, o Plano de Desenvolvimento da Educação (PDE), a fim de melhorar a educação oferecida às crianças, jovens e adultos do país. Com o objetivo de identificar quais as redes de ensino municipais e as escolas que apresentam maiores fragilidades no desempenho escolar, necessitando de maior atenção e até apoio financeiro, o PDE apresenta o Índice de Desenvolvimento da Educação Básica (Ideb). Ele combina dois indicadores: fluxo escolar, passagem dos alunos pelas séries sem repetir, e desempenho dos estudantes, avaliado por meio da Prova Brasil, que possibilita retratar a realidade de cada escola, em cada município, 
avaliando as competências construídas e as habilidades desenvolvidas em leitura, a fim de se promover a melhoria da qualidade da leitura em sala de aula.

Diante do exposto, constata-se que vários documentos oficiais tratam da prática da leitura, assim como já mencionado:

- Parâmetros Curriculares Nacionais - PCN (BRASIL, 1998);

- Diretrizes Curriculares Estaduais - DCE (PARANÁ, 2008);

- Plano de Desenvolvimento da Educação-PDE (BRASIL, 2009a);

- Orientações para professor - SAEB/Prova Brasil (BRASIL, 2009b).

Esses são os documentos que fundamentam a elaboração das avaliações nacionais, como a Prova Brasil.

Para que avaliações como a Prova Brasil sejam realizadas, exigese a construção de uma matriz de referência que dê transparência e legitimidade ao processo de avaliação, informando aos indivíduos, às escolas e aos órgãos envolvidos aquilo que será avaliado. A Matriz de Referência é o "referencial curricular do que será avaliado em cada disciplina e série, informando as competências e habilidades esperadas dos alunos" (BRASIL, 2009a). Com base nessas informações, alguns direcionamentos são dados a respeito do Saeb/Prova Brasil (BRASIL, 2009b). De acordo com esse material, não é possível construir instrumentos de avaliação sem que se reporte à experiência da disciplina em sala de aula. Logo, a avaliação de Língua Portuguesa na área de leitura deve considerar o fazer pedagógico, pensando em um ensino voltado para a autonomia, para a participação cidadã, norteado para:

a) Domínio do uso da língua materna, nas suas manifestações orais e escritas, tanto para a leitura de textos quanto para a sua produção;

b) Reflexão analítica e crítica sobre a linguagem como fenômeno social, histórico, cultural, político, etc.;

c) Visão crítica dos fenômenos linguísticos no uso dos recursos gramaticais a serviço dos propósitos comunicativos do produtor do texto. (BRASIL, 2009b, p. 13). 
Cabe ressaltar que esses aspectos são determinações para a sala de aula, não sendo apresentados diretamente nas avaliações oficiais, como a Prova Brasil. Espera-se que esses fatores sejam do domínio do aluno no momento de realização de qualquer avaliação, haja vista que levam à leitura crítica do texto. $\mathrm{O}$ primeiro elemento destacado é o domínio por parte do aluno do uso da língua materna em textos orais e escritos, ou seja, ao dominar a linguagem, o estudante torna-se capaz de compreender, interpretar e produzir textos, tornando-se um sujeito ativo diante dos usos da linguagem. Diante do domínio da língua, pode-se promover a reflexão analítica e crítica sobre a linguagem, vendo-a como fenômeno social, retomando os dizeres de Bakhtin (2003), que a concebe como um meio de interação. Após dominar e refletir sobre a língua, pode-se alcançar a visão crítica dos fenômenos linguísticos, em relação, por exemplo, ao uso de recursos gramaticais empregados em textos.

Vê-se, assim, o encadeamento de ações que levam a uma visão mais crítica do que se lê, possibilitando-se a formação e o desenvolvimento de um sujeito competente no domínio da linguagem, retomando os dizeres expostos nos PCN (BRASIL, 1998), haja vista que

Essas matrizes têm por referência os Parâmetros Curriculares Nacionais e foram construídas a partir de uma consulta nacional aos currículos propostos pelas Secretarias Estaduais de Educação e por algumas redes municipais. O Inep consultou também professores regentes das redes municipal, estadual e privada e, ainda, examinou os livros didáticos mais utilizados para essas séries, nas citadas redes. (BRASIL, 2009a, p. 17).

Os dados a respeito da Matriz de Referência, disponibilizados pelo próprio governo, por meio, por exemplo, do Plano de Desenvolvimento da Educação (BRASIL, 2009a) e das Orientações para professor - SAEB/ Prova Brasil (BRASIL, 2009b), possibilitam que se elabore uma visão geral do que se espera em relação à leitura em sala de aula. Acredita-se que o ensino de língua materna deve-se voltar à função social da língua, não sendo concebida como algo individual: "não aprendemos a Língua Portuguesa na escola para cumprir uma necessidade individual. 
Aprendemos a ler e a escrever porque estamos inseridos em um grupo social, entendendo que a língua só se realiza, efetivamente, na interação entre sujeitos." (BRASIL, 2009b, p. 13). A língua é vista, então, como uma forma de interação, fazendo com que a leitura também seja concebida dessa forma, mediante o processo de interação entre leitor e texto. Para que o leitor seja considerado competente, precisa dominar habilidades que o capacitem a viver em sociedade, atuando nas mais diversas situações sociais de comunicação: "Daí a importância de promover-se o desenvolvimento, no aluno, da capacidade de produzir e compreender textos dos mais diversos gêneros, em diferentes situações comunicativas" (BRASIL, 2009a, p. 19). Constata-se, assim, que a leitura é fruto da interação que permite ao leitor se posicionar ativamente diante do enunciado, construindo significados e produzindo sentidos para aquilo que lê.

Nesse sentido, a Matriz de Referência tem como foco a leitura, pois

Ler é uma atividade complexa que faz amplas solicitações ao intelecto e às habilidades cognitivas superiores da mente: reconhecer, identificar, agrupar, associar, relacionar, generalizar, abstrair, comparar, deduzir, inferir, hierarquizar. Não está em pauta apenas a simples decodificação, mas a apreensão de informações explícitas e implícitas e de sentidos subjacentes, e a construção de sentidos que dependem de conhecimentos prévios a respeito da língua, dos gêneros, das práticas sociais de interações, dos estilos, das formas de organização textual. (INEP, 2009)

Observa-se que a prática da leitura é considerada complexa, uma vez que envolve elementos, como: texto, leitor e autor, representado pelo texto. Ao afirmar que no momento da leitura dominam-se as habilidades de "reconhecer, identificar, agrupar", fazse referência à perspectiva de leitura centrada no texto, pois cabe ao aluno extrair informações, decodificar elementos, práticas evidentes no início do trabalho com a leitura. Porém, afirma-se que a leitura não se restringe à "simples decodificação", sendo preciso que o aluno associe, relacione, generalize e abstraia elementos do texto, evidenciando a perspectiva de leitura do leitor. Nela, espera-se que o aluno relacione 
o texto com o seu conhecimento de mundo, trazendo seu posicionamento para aquilo que lê. De certa forma, esse diálogo entre o texto e o leitor faz com que se alcance a interação em leitura, momento em que o aluno compara, deduz, infere e promove a hierarquia de informações porque já demonstra certo domínio delas. Ele já foi capaz de construir sentidos, observando seus conhecimentos prévios, o gênero utilizado, as formas de organização textual entre outros elementos. Vê-se, assim, que esses pressupostos sobre leitura fundamentam-se em uma visão processual, partindo do texto até alcançar a interação. Logo, o ensino deve voltar-se para a função social da língua, de modo a contribuir para a formação e a participação do indivíduo no mundo letrado.

Os testes oficiais, como a Prova Brasil, tem como foco a leitura e como objeto de estudo o texto, apresentando o objetivo de verificar se os estudantes são capazes de apreendê-lo como construção de conhecimento em diferentes níveis de compreensão, análise e interpretação.

A Matriz de Língua Portuguesa, ${ }^{2}$ estruturalmente, divide-se em duas dimensões: uma denominada de Objeto do Conhecimento, em que são listados os seis tópicos; e outra, denominada Competência, com descritores que indicam habilidades a serem avaliadas em cada tópico:

\section{Tópico I. Procedimentos de Leitura}

${ }^{3}$ D1 - Localizar informações explícitas em um texto.

D3 - Inferir o sentido de uma palavra ou expressão.

D4 - Inferir uma informação implícita em um texto.

D6 - Identificar o tema de um texto.

D11 - Distinguir um fato da opinião relativa a esse fato.

${ }^{2}$ Destaca-se a Matriz de Referência da $4^{a}$ série do ensino Fundamental para a visualização dos elementos que a compõem, uma vez que sua análise será realizada nas seções seguintes.

${ }^{3}$ Abrevia-se o termo Descritor com a letra D, juntamente com a indicação numérica de seu nível. 
Tópico II. Implicações do Suporte, do Gênero e /ou do Enunciador na Compreensão do Texto

D5 - Interpretar texto com auxílio de material gráfico diverso (propagandas, quadrinhos, foto, etc.).

D9 - Identificar a finalidade de textos de diferentes gêneros.

\section{Tópico III. Relação entre Textos}

D15 - Reconhecer diferentes formas de tratar uma informação na comparação de textos que tratam do mesmo tema, em função das condições em que ele foi produzido e daquelas em que será recebido.

\section{Tópico IV. Coerência e Coesão no Processamento do Texto}

D2 - Estabelecer relações entre partes de um texto, identificando repetições ou substituições que contribuem para a continuidade de um texto.

D7 - Identificar o conflito gerador do enredo e os elementos que constroem a narrativa.

D8 - Estabelecer relação causa / conseqüência entre partes e elementos do texto.

D12 - Estabelecer relações lógico-discursivas presentes no texto, marcadas por conjunções, advérbios, etc.

Tópico V. Relações entre Recursos Expressivos e Efeitos de Sentido

D13 - Identificar efeitos de ironia ou humor em textos variados.

D14 - Identificar o efeito de sentido decorrente do uso da pontuação e de outras notações.

\section{Tópico VI. Variação Linguística}

D10 - Identificar as marcas lingüísticas que evidenciam o locutor e o interlocutor de um texto.

(INEP, 2008, online, acesso em: 20/06/2009).

Observa-se que não são avaliados conteúdos específicos de língua portuguesa na etapa de escolarização, sendo esta a peculiaridade 
de uma matriz que avalia a competência leitora (BRASIL, 2009b). Os tópicos aglutinam seus descritores de habilidades apresentando as condições necessárias para um adequado processamento da leitura pelo indivíduo. De acordo com Brasil (2009b), os três primeiros tópicos (Tópico I. Procedimentos de Leitura ; Tópico II. Implicações do Suporte, do Gênero e / ou do Enunciador na Compreensão do Texto ; Tópico III. Relação entre Textos) estão ligados ao texto em sua "estrutura arquitetônica"; os três últimos (Tópico IV. Coerência e Coesão no Processamento do Texto; Tópico V. Relações entre Recursos Expressivos e Efeitos de Sentido; Tópico VI. Variação Linguística), aos recursos linguísticos que contribuem para a construção do texto.

De acordo com Brasil (2009c), todo o trabalho com a leitura deve levar à formação e desenvolvimento de leitores autônomos,

O leitor proficiente e autônomo antecipa o texto, infere informações ou ações que não estão ditas, percebe e valida ou não - a posição do(s) autor (es) com base em informações colhidas em outros textos ou outras fontes de informação e, muitas vezes, reformula suas próprias concepções a partir das leituras. (BRASIL, 2009c, p. 24).

Para que essa leitura interacionista ocorra, é necessária uma série de habilidades e competências, cabendo à escola proporcionar aos alunos todas as oportunidades de acesso às práticas sociais que se realizam, principalmente, por meio do texto escrito. $O$ aluno, que demonstra todas as habilidades demarcadas, testou hipóteses, comparou, juntou informações, refletiu sobre o que leu, resgatou suas memórias, enfim, dialogou com o texto e consigo mesmo, respondendo ativamente ao esperado.

Para complementar a visão de leitor autônomo, as Orientações para o Professor - SAEB/Prova Brasil (BRASIL, 2009b, p. 13) acrescentam que o sujeito competente é "capaz de compreender textos orais e escritos, de posicionar-se criticamente diante do que lê e ouve, de ler produzindo sentidos, entendendo o propósito comunicativo do produtor do texto, formulando hipóteses de leitura.”. Vê-se, assim, que essa visão traz consigo a leitura como um ato social e não uma atividade individual, pois, para as Orientações (BRASIL, 2009b), 
aprende-se a ler e a escrever, porque os sujeitos inserem-se em um grupo social que utiliza a leitura e a escrita, numa nítida retomada do pensamento bakhtiniano de que o indivíduo é o que o seu grupo social determina que seja, não só em relação à linguagem, como também, em relação aos comportamentos (BAKHTIN/VOLOCHINOV, 1992).

Várias características, que foram expostas a respeito dos documentos oficiais que fundamentam a construção da Prova Brasil, não são possíveis de serem mensuradas por meio da avaliação, pois supõem, além da interação com o texto, a interação com outros indivíduos. A Prova Brasil é realizada por escrito, individualmente, não prevendo, portanto, o compartilhamento de informações sobre o material de leitura entre diferentes leitores. De qualquer forma, de acordo com as Orientações para o Professor - SAEB/Prova Brasil (BRASIL, 2009b, p. 13), ainda que esses elementos não sejam foco dessa avaliação, são constitutivos da proficiência leitora e devem ser tomados como objeto de ensino nas práticas escolares de sala de aula. Dessa forma, por fim, destacam-se as características de leitura demarcadas nos documentos do Saeb:

O ensino da Língua Portuguesa-leitura deve-se voltar à função social da língua.

A língua é vista como interação.

A leitura é fruto da interação.

O leitor se posiciona ativamente diante do enunciado.

O leitor constrói significados e produz sentidos.

A leitura leva à formação de leitores autônomos.

O leitor antecipa o texto.

O leitor infere informações.

O leitor percebe, avalia e reformula concepções.

O leitor é capaz de compreender textos orais e escritos.

O leitor é capaz de posicionar-se.

A leitura demanda domínio de capacidades que precisam ser ensinadas.

A leitura promove o trabalho com os gêneros.

Quadro 3 - Características sobre a leitura nos documentos do Saeb 


\section{$4 \mathrm{O}$ conceito de leitura nos documentos oficiais}

Ao longo das análises, foi identificado que o conceito de leitura que perpassa pelos documentos oficiais investigados é a perspectiva interacionista. A partir das discussões teóricas já sistematizadas pela literatura de Linguística Aplicada, a partir de autores como Dell'Isola (1996), Kleiman (1996, 2000), Leffa (1996) e Menegassi \& Ângelo (2005), as características do conceito de leitura interacionista são elencadas no Quadro 4, num contraponto com aquelas observadas nos documentos oficiais.

\begin{tabular}{|c|c|c|c|}
\hline $\begin{array}{c}\text { Características } \\
\text { teóricas }\end{array}$ & PCN (1998) & DCEs (2008) & $\begin{array}{l}\text { Documentos do } \\
\text { Saeb }\end{array}$ \\
\hline $\begin{array}{l}\text { O processo de leitura } \\
\text { promove o diálogo } \\
\text { entre leitor e texto; }\end{array}$ & $\begin{array}{llr}\text { A leitura leva } & \text { à } \\
\text { formação } & \text { e } & \text { ao } \\
\text { desenvolvimento } & \text { de } \\
\text { leitores competentes; }\end{array}$ & $\begin{array}{l}\text { A leitura é uma } \\
\text { condição de atividade } \\
\text { e acontecimento } \\
\text { social; }\end{array}$ & $\begin{array}{l}\text { O ensino da Língua } \\
\text { Portuguesa deve-se } \\
\text { voltar à função social } \\
\text { da língua; }\end{array}$ \\
\hline $\begin{array}{l}\text { O processo de leitura } \\
\text { promove a construção } \\
\text { de uma compreensão; }\end{array}$ & $\begin{array}{l}\text { A leitura é um } \\
\text { processo coletivo; }\end{array}$ & $\begin{array}{l}\text { A leitura considera } \\
\text { aspectos sociais e } \\
\text { históricos em que o } \\
\text { sujeito está inserido; }\end{array}$ & $\begin{array}{l}\text { A língua é vista como } \\
\text { interação; }\end{array}$ \\
\hline $\begin{array}{l}\text { O processo de leitura } \\
\text { promove uma } \\
\text { resposta ativa ao que } \\
\text { é exposto; }\end{array}$ & $\begin{array}{l}\text { A leitura é constituída } \\
\text { de etapas; }\end{array}$ & $\begin{array}{l}\text { A leitura permite o } \\
\text { contato do aluno com } \\
\text { a linguagem nas } \\
\text { diferentes esferas } \\
\text { sociais; }\end{array}$ & $\begin{array}{l}\text { A leitura é fruto da } \\
\text { interação; }\end{array}$ \\
\hline $\begin{array}{lll}\text { A leitura é } & \text { um } \\
\text { processo ativo; } & \end{array}$ & $\begin{array}{lr}\text { O leitor realiza um } \\
\text { trabalho ativo } & \text { de } \\
\text { construção } & \text { do } \\
\text { significado do texto; }\end{array}$ & $\begin{array}{l}\text { A leitura é de } \\
\text { dimensão dialógica; }\end{array}$ & $\begin{array}{l}\text { O leitor se posiciona } \\
\text { ativamente diante do } \\
\text { enunciado; }\end{array}$ \\
\hline $\begin{array}{lc}\text { O leitor realiza } & \text { um } \\
\text { trabalho } & \text { de } \\
\text { construção } & \text { de } \\
\text { significado do texto; }\end{array}$ & $\begin{array}{l}\text { O leitor tem objetivos } \\
\text { de leitura; }\end{array}$ & $\begin{array}{l}\text { A ação pedagógica de } \\
\text { leitura deve pautar-se } \\
\text { na interlocução; }\end{array}$ & $\begin{array}{l}\mathrm{O} \quad \text { leitor constrói } \\
\text { significados e produz } \\
\text { sentidos; }\end{array}$ \\
\hline $\begin{array}{l}\text { A leitura é um } \\
\text { processo determinado } \\
\text { pelas condições } \\
\text { sociais do leitor, } \\
\text { sendo variável, } \\
\text { possibilitando que um } \\
\text { texto apresente } \\
\text { diferentes leituras; }\end{array}$ & $\begin{array}{l}\text { A leitura implica } \\
\text { compreensão. }\end{array}$ & $\begin{array}{lr}\begin{array}{lr}\text { A leitura } & \text { envolve } \\
\text { demandas } & \text { sociais, } \\
\text { históricas, } & \text { políticas, } \\
\text { econômicas, } & \\
\text { pedagógicas } & \text { e } \\
\text { ideológicas de um } \\
\text { momento; }\end{array} & \\
\end{array}$ & $\begin{array}{l}\text { A leitura leva à } \\
\text { formação de leitores } \\
\text { autônomos; }\end{array}$ \\
\hline $\begin{array}{l}\text { O leitor busca extrair, } \\
\text { primeiramente, um } \\
\text { significado existente } \\
\text { para depois produzir } \\
\text { um sentido; }\end{array}$ & & $\begin{array}{l}\text { Ao ler, o indivíduo } \\
\text { busca } \\
\text { experiências e suas } \\
\text { conhecimentos } \\
\text { prévios; }\end{array}$ & $\begin{array}{l}\mathrm{O} \text { leitor antecipa o } \\
\text { texto; }\end{array}$ \\
\hline
\end{tabular}




\begin{tabular}{|c|c|c|}
\hline $\begin{array}{l}\text { A leitura é um espaço } \\
\text { de respostas a outros } \\
\text { textos } \\
\text { contemplados, } \\
\text { configurando } \\
\text { contra-palavra; }\end{array}$ & $\begin{array}{l}\text { A leitura implica uma } \\
\text { resposta do leitor ao } \\
\text { que lê; }\end{array}$ & $\begin{array}{l}\mathrm{O} \text { leitor } \\
\text { informações; }\end{array}$ \\
\hline $\begin{array}{l}\text { A leitura pode } \\
\text { promover a formação } \\
\text { do leitor como um } \\
\text { co-produtor do texto; }\end{array}$ & $\begin{array}{l}\text { A leitura acontece } \\
\text { num tempo e num } \\
\text { espaço; }\end{array}$ & $\begin{array}{l}\text { O leitor percebe, } \\
\text { avalia e reformula } \\
\text { concepções; }\end{array}$ \\
\hline $\begin{array}{l}\text { O leitor é um ser } \\
\text { ativo que busca } \\
\text { informações, } \\
\text { extraindo do texto o } \\
\text { que condiz com seu } \\
\text { objetivo, atribuindo } \\
\text { seu conhecimento } \\
\text { prévio e produzindo } \\
\text { um sentido; }\end{array}$ & $\begin{array}{l}\text { O leitor se constitui } \\
\text { como sujeito; }\end{array}$ & $\begin{array}{l}\text { O leitor é capaz de } \\
\text { compreender textos } \\
\text { orais e escritos; }\end{array}$ \\
\hline $\begin{array}{l}\text { A leitura possibilita ao } \\
\text { aluno o seu } \\
\text { amadurecimento } \\
\text { como sujeito crítico; }\end{array}$ & & $\begin{array}{l}\text { O leitor é capaz de } \\
\text { posicionar-se; }\end{array}$ \\
\hline $\begin{array}{l}\text { O processo de leitura } \\
\text { pode formar um leitor } \\
\text { crítico; }\end{array}$ & & $\begin{array}{lr}\text { A leitura } & \text { demanda } \\
\text { domínio } & \text { de } \\
\text { capacidades } & \text { que } \\
\text { precisam } & \text { ser } \\
\text { ensinadas; } & \end{array}$ \\
\hline $\begin{array}{l}\text { A leitura crítica, que } \\
\text { caracteriza a formação } \\
\text { de um leitor } \\
\text { crítico/competente, é } \\
\text { concebida como uma } \\
\text { prática social; }\end{array}$ & & $\begin{array}{l}\text { A leitura promove o } \\
\text { trabalho com os } \\
\text { gêneros. }\end{array}$ \\
\hline $\begin{array}{l}\text { O leitor crítico realiza } \\
\text { a prática da seleção, } \\
\text { ou seja, seleciona } \\
\text { aquilo que lhe faz } \\
\text { sentido; }\end{array}$ & & \\
\hline
\end{tabular}

Quadro 4-Perspectiva interacionista de leitura nos documentos oficiais

De modo geral, após o levantamento dos aspectos presentes nos documentos oficiais que fundamentam o trabalho com a leitura, constata-se a visão de leitura como um processo, uma vez que a linguagem é tida como uma forma de interação entre os sujeitos, possibilitando sua atuação nas diversas situações sociais. A partir dos PCN (BRASIL, 1998), as características de tal conceito de leitura vão sendo ampliados e desenvolvidos, assim como se constata nas DCE 
(PARANÁ, 2008) e nos Documentos do Saeb, visando à melhoria do processo de ensino e de aprendizagem da leitura. Enquanto nos PCN (BRASIL, 1998) a leitura era vista como meio que leva à formação e ao desenvolvimento do leitor competente, tem-se, nas DCE (PARANÁ, 2008), a ampliação da visão sobre leitura como uma condição de atividade humana, um acontecimento social. A partir disso, os Documentos do Saeb levam os conceitos para o contexto escolar, considerando-se que o ensino da Língua Portuguesa deve se voltar à função social da língua.

A aprendizagem e o domínio da prática da leitura fazem com que os sujeitos "exerçam seus direitos, possam trabalhar e participar da sociedade com cidadania, informar-se e aprender coisas novas ao longo de toda a vida.” (BRASIL, 2006, p. 7). Diante disso, justifica-se a necessidade de estudos constantes a respeito da leitura, por meio de avaliações oficiais que permitam o levantamento do quadro atual a respeito do assunto.

\section{Referências}

BAKHTIN, M. Estética da criação verbal. 4. ed. São Paulo: Martins Fontes, 1997; 2003.

BAKHTIN, M./VOLOCHINOV, M. Marxismo e Filosofia da linguagem. 6. ed. São Paulo: Hucitec, 1992.

BRASIL. MEC. PDE: Plano de Desenvolvimento da Educação: Prova Brasil: ensino fundamental: matrizes de referência, tópicos e descritores. Brasília: MEC, SEB; INEP, 2009a.

. MEC. Orientações para professores - SAEB/Prova Brasil. Brasília: MEC, SEB; INEP, 2009b.

S. E. B. Pró-letramento: alfabetização e linguagem. Brasília, 2007, p. 1-50. fascículo 2 - Alfabetização e letramento: Questões sobre avaliação. 
SEF. Parâmetros Curriculares Nacionais: Língua Portuguesa: $5^{\mathrm{a}}$. a 8a. Série. Brasília: SEF, 1998.

MEC. LDB: Lei de Diretrizes e Bases da Educação Nacional. 1996. Disponível em: <http://portal.mec.gov.br/arquivos/pdf/ ldb.pdf>. Acesso em: 25 jun. 2008.

DELL'ISOLA, R. L. P. A interação sujeito-linguagem em leitura. In: MAGALHÃES, I. (org.). As múltiplas faces da linguagem. Brasília: UNB, 1996.

A avaliação de leitura de textos no ensino de Língua Portuguesa. In: Reflexões sobre a lingua portuguesa: ensino e pesquisa. Campinas: Pontes, 1997, p. 53-58.

INEP. Qualidade da educação: uma nova leitura do desempenho dos estudantes da $4^{\text {a }}$ série do Ensino Fundamental. Disponível em: <www.inep.gov.br>. Acesso em: 24 mar. 2009.

SAEB - 2005. Primeiros resultados: Médias de desempenho do SAEB/2005 em perspectiva comparada. <www.inep.gov.br> 2007. Acesso em: 10 maio 2009.

. Matriz de Referência. 2008. Disponível em: <www.inep.gov.br/ $\mathrm{basica} / \mathrm{saeb} / \mathrm{matrizes} /$ topicos_descritores_pot.htm.>. Acesso em 15 maio 2009.

- Qualidade da educação: uma nova leitura do desempenho dos estudantes da $4^{\text {a }}$ série do Ensino Fundamental. 2003. Disponível em: <www.inep.gov.br>. Acesso em: 24 mar. 2009.

KLEIMAN, A. Texto e leitor: aspectos cognitivos da leitura. 7. ed. Campinas, SP: Pontes, 2000.

. Oficina de leitura: teoria e prática. Campinas: Pontes, 1996.

LEFFA, V.J. Aspectos da leitura. Porto Alegre: Sagra Luzzano, 1996. 
MENEGASSI, R. J. O leitor e o processo de leitura. In: GRECO, E. AL.; GUIMARÃES, T. B.; Leitura: aspectos teóricos e práticos. Maringá: Eduem, 2010, p. 35-60.

.; ANGELO, C. M. P. Conceitos de leitura. In: MENEGASSI, R. J. (Org). Leitura e ensino. Maringá: Eduem, 2005, p. 15-40.

PARANÁ, Secretaria de Estado de Educação. Diretrizes Curriculares da Educação Básica - Língua Portuguesa. Paraná, 2008.

SOUZA, I. R. Conceitos bakbtinianos no contexto da reformulação curricular da educação básica do Paraná. 2010. 103f. Dissertação (Mestrado) Universidade Estadual de Maringá. Programa de Pós-graduação em Letras, 2010. 